\title{
Intermonsoon Variation of Physical Characteristics and Current Circulation along the East Coast of Peninsular Malaysia
}

\author{
Mohd Fadzil Mohd Akhir, ${ }^{1,2}$ Nur Zurairah Zakaria, ${ }^{1}$ and Fredolin Tangang ${ }^{3}$ \\ ${ }^{1}$ Faculty of Maritime Studies and Marine Science, Universiti Malaysia Terengganu, 21030 Kuala Terengganu, Terengganu, Malaysia \\ ${ }^{2}$ Institute of Oceanography, Universiti Malaysia Terengganu, 21030 Kuala Terengganu, Terengganu, Malaysia \\ ${ }^{3}$ Research Centre for Tropical Climate Change System (IKLIM), Faculty of Science and Technology, Universiti Kebangsaan Malaysia, \\ 43600 Bangi, Selangor, Malaysia
}

Correspondence should be addressed to Mohd Fadzil Mohd Akhir; mfadzil@umt.edu.my

Received 13 May 2013; Revised 15 November 2013; Accepted 18 November 2013; Published 21 January 2014

Academic Editor: Leonard Pietrafesa

Copyright (C) 2014 Mohd Fadzil Mohd Akhir et al. This is an open access article distributed under the Creative Commons Attribution License, which permits unrestricted use, distribution, and reproduction in any medium, provided the original work is properly cited.

\begin{abstract}
Data from eight cruises spanning from 2002 to 2007 are used to investigate the seasonal changes in water characteristics and current circulation in southern South China Sea along the East Coast of Peninsular Malaysia. The surveys were made during two intermonsoon periods which are during March/April and September/October. In addition, monthly sea surface temperature from Moderate Resolution Imaging Spectroradiometer (MODIS) is used to provide wider coverage of spatial and temporal for seasonality study. Overall, the area shares different physical properties between the two seasons. During September/October temperature is lower and salinity is higher compared to the data during Mac/April/May. The current along the East Coast of Peninsular Malaysia also shows seasonality, with dominant current flow southward during Mac/April and northward during September/October.
\end{abstract}

\section{Introduction}

The southern South China Sea (SSCS) is a tropical marginal sea with a complex geographical setting in Southeast Asia. It is located between the western Pacific and the eastern Indian Ocean. The SSCS connects with the Sulu Sea in the northeast through the Mindoro and Balabac Straits, with the Java Sea in the south through the Karimata Straits, and with the Andaman Sea in the west through the Malacca Strait. It is basically a shallow continental basin with the average depth of $60 \mathrm{~m}$.

The climate over SSCS is controlled by South China Sea (SCS) monsoon [1]. Weaker southwesterly summer monsoon winds occur from April to August which drives a northward coastal jet off Vietnam. Meanwhile, stronger northeasterly winter monsoon winds occur from November to March causing a southward coastal jet in the SCS [2]. According to Akhir and Chuen [3], during northeast monsoon current moves southward along Peninsular Malaysia and moves in the opposite direction during southwest monsoon. In general, the pattern of sea surface circulation is different according to monsoon seasons. During southwest monsoon, the main surface current moves from the Indonesian Seas (Karimata and Malacca Straits) to the north (South China Sea). On the opposite, the sea surface circulation comes from the north to the south through the small islands during the northeast monsoon [4].

There have been only a few references related to the observational study of SSCS circulation and physical characteristics especially around Malaysian waters. The most intensive hydrographic observation which involves Malaysian waters has been carried out by SEAFDEC (South East Asian Fisheries Development Centre) in September 1995 and April-May 1996. It covered the western part of the Gulf of Thailand and the East Coast of Peninsular Malaysia. The understanding of the current movement and hydrographic profile of this region so far relies on limited investigations and those were undertaken mostly between 1994 and 2001 [5-7]. Fang et al. [8] provided additional understanding of the southern part of SCS; however, their studies areas are still not including 
the Malaysian coastal waters. Although all of the previous studies provided limited information of this region, none of them addressed adequately the annual variability of the system, which is greatly influenced by the monsoons.

The above-mentioned studies mostly focused on an individual parameter or event using data of short temporal and small scale coverage. With the availability of more than 10 years of satellite-observed sea surface temperature (SST), it is now worthwhile to make an integrated analysis of these satellite-observed sea surface fields to provide more systematic views for the trends and interannual variability in SCS. As an East Asian marginal sea, seasonality dominates the variability. In this study, we also use Aqua Moderate Resolution Imaging Spectroradiometer (MODIS) SST to reveal the seasonal variations of temperature. Aqua satellite (EOS PM-1) was successfully launched by NASA in May 2002 and is still operational.

The objectives of this study are to describe the seasonal changes in water characteristics and current circulation during intermonsoon period (March/April and September/October) of which the collection of field data lies. It is unclear from the previous study if monsoon season has any influence at this particular period of time. The study will try to demonstrate the characteristics of particular study period to provide better understanding of the seasonal variations of physical characteristics that occur at the southern SCS especially along the coast of East Peninsular Malaysia.

\section{Materials and Methods}

2.1. Field Observation. The analysis focuses on field data collected along the East Coast of Peninsular Malaysia over six-year period from 2002 to 2007. The cruises were conducted by the Institute of Oceanography (INOS), Universiti Malaysia Terengganu, in its effort to construct a proper data centre for oceanographic research in Malaysian coastal waters. Overall, there are 98 stations which spread in an area from $1^{\circ} \mathrm{N}$ to $6.5^{\circ} \mathrm{N}$ and $102^{\circ} \mathrm{E}$ to $105^{\circ} \mathrm{E}$ (Figure 1). The network of stations was constructed using transect lines, which range from near shore up to $50 \mathrm{~km}$ offshore. The data were taken twice where each data represented a particular period of the year (most of the data were taken during March/April and September/October).

During the cruises, standard current meter was used to obtain current data while Hydrolab Data Sonde 4a was also employed to acquire temperature and salinity. The spatial distributions of datasets having adequate resolution were achieved by choosing sufficiently large number of stations, so as to provide a clear representation of physical parameters and their seasonal variations in the study area.

For analysis purposes, the study area is divided into four sections, which are sections A, B, C, and D. Section A covers the upper region which is Kuala Terengganu waters, followed by section B which is Dungun waters, while section $\mathrm{C}$ covers Pahang waters and the lowest region is Johor which is named as section $\mathrm{D}$. Composite technique is used to comprehend different years of data into specific seasonal aspects of certain months, which are in this case March/April and September/October. Based on the obtained Hydrolab

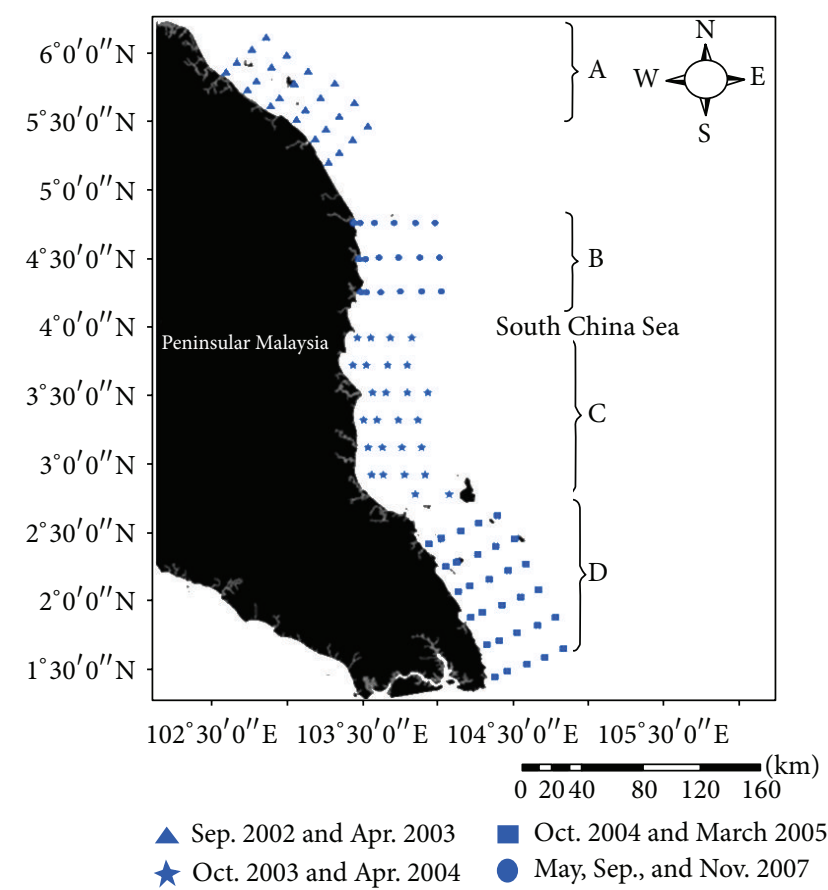

FIGURE 1: Map of study site and distribution of stations.

Data Sonde 4a data, the temperature and salinity distribution at the $5 \mathrm{~m}$ are mapped. Meanwhile, the vertical sectional distributions of temperature and salinity are also plotted.

2.2. Satellite Data. In this study, monthly SST images from Aqua MODIS (Level 3) data of $4 \mathrm{~km}$ resolution were used as an additional data to provide comprehensive overview especially on the surface temperature characteristics. With the field data cover only up to $50 \mathrm{~km}$ offshore, MODIS data analysis will provide wider coverage of spatial and temporal data for seasonality study. The SST satellite images were downloaded from OceanColor website (http://oceancolor.gsfc.nasa.gov/) provided by NASA.

\section{Results}

3.1. Physical Characteristics. Surface temperature distributions were plotted based on the particular year of the cruise trip. Figure 2 demonstrates contour for temperature in March/April and September/October. There are some important difference that can be seen when we consider specific locations as divided by this study. Surface temperature in the offshore area of Pahang (Figure 2(c)) and Johor (Figure 2(d)) recorded low temperature during March/April especially in Johor. The lowest recorded value reaches $28^{\circ} \mathrm{C}$ and most of the offshore area are cooler comparatively. On the other hand, temperature at Kuala Terengganu and Dungun is slightly higher with up to $1-2^{\circ} \mathrm{C}$ difference. Along the coast from Terengganu to Johor, coastal area shows higher temperature reading comparatively to the offshore area. 

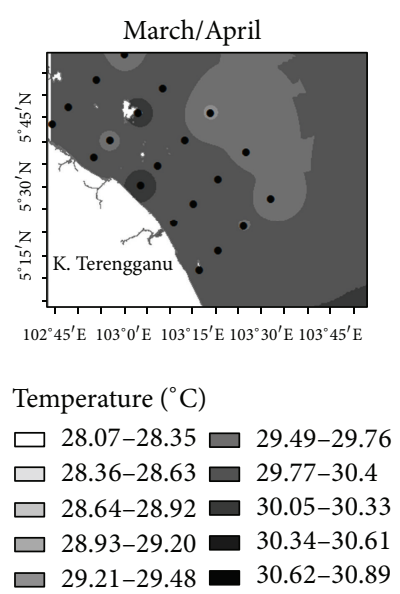

(a)
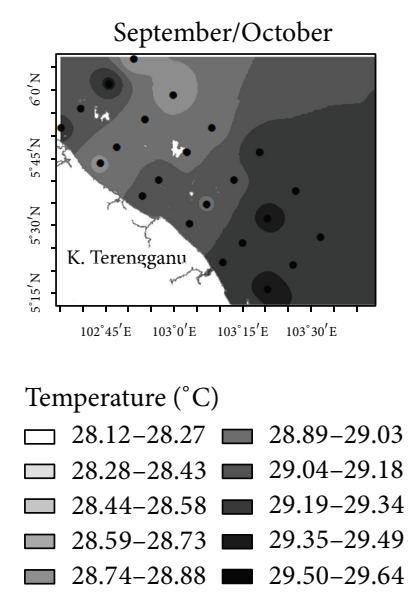

(e)

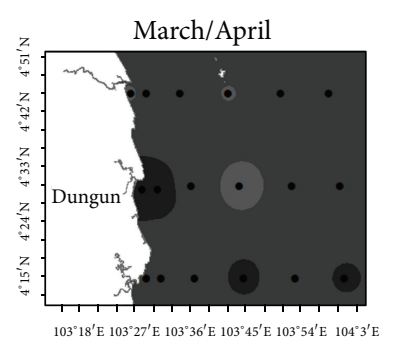

Temperature $\left({ }^{\circ} \mathrm{C}\right)$

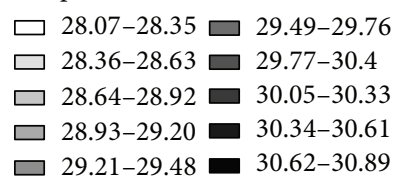

(b)

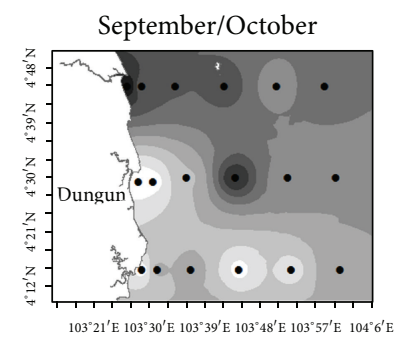

Temperature $\left({ }^{\circ} \mathrm{C}\right)$

$\square$ 28.12-28.27 $\square$ 28.89-29.03

$\square$ 28.28-28.43 $\square$ 29.04-29.18

$\square$ 28.44-28.58 29.19-29.34

$\square$ 28.59-28.73 29.35-29.49

$\square 28.74-28.88 \square 29.50-29.64$

(f)
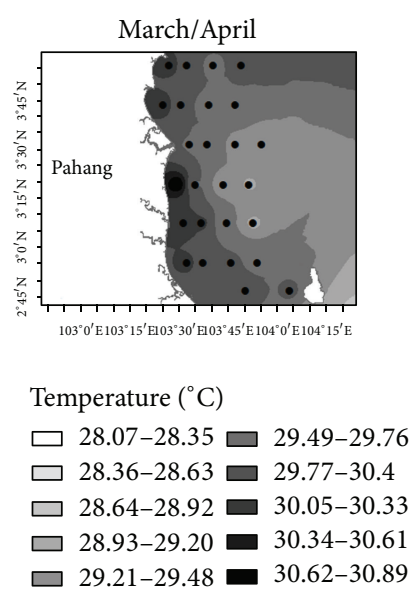

(c)
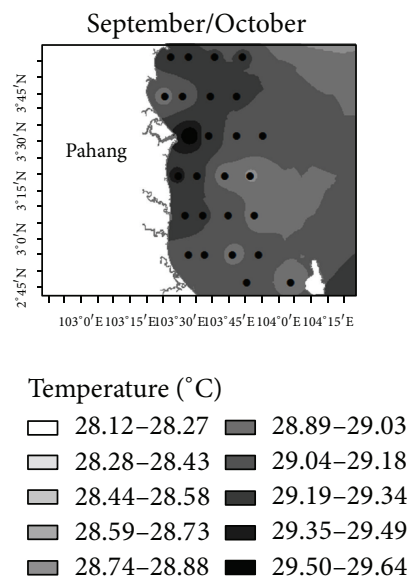

(g)
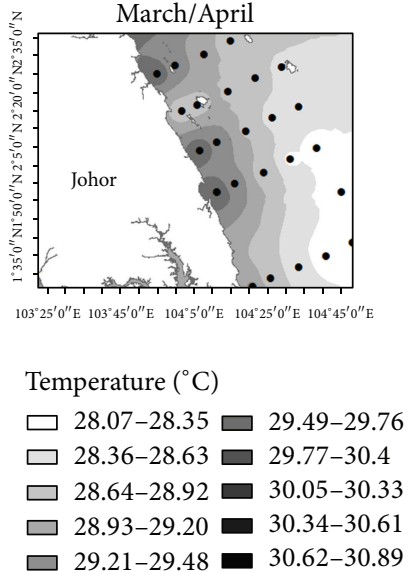

(d)
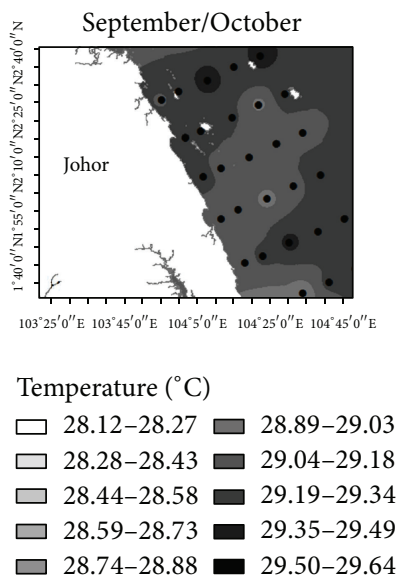

(h)

FIgURE 2: Temperature distribution according to location during March/April and September/October.

The temperature changes are mostly meridional except for few areas. Nevertheless, not much can be described during this time. Pahang and Johor temperature distribution is not consistent, but, in general, coastal water shows temperature decreasing towards south.

Figure 3 shows salinity distribution on the surface. During March/April period, salinity recorded at Kuala Terengganu (Figure 3(a)) water is the lowest with salinity value between $31.5 \mathrm{ppt}$ and $32.1 \mathrm{ppt}$. In other places, salinity is more than 1 ppt higher than Kuala Terengganu and in Pahang water (Figure 3(c)) recorded the highest salinity which reaches more than $34.7 \mathrm{ppt}$. Salinity changing pattern is similar to temperature where March/April recorded inshore-offshore changes while September/October changes is meridional. The meridional changes are clear in Terengganu, Pahang, and Johor, where northern and southern part share difference of nearly 1 ppt.

Temperature and salinity cross-sections at the selected transect during March/April/May and September/October were presented in Figures 4-7. Transects for this analysis were chosen based on transects which are assumed to have no significant effect from freshwater (in this case, away from main river outflow region). As shown in Figures 4 and 5, all cross-sections during March/April recorded higher temperature and lower salinity which represent the characteristics of low density water. Comparatively, low temperature water and high salinity were consistent throughout the cross-sections during September/October (Figures 6 and 7). This water characterizes higher density water than the previous reading. The difference of temperature reading is around $0.5^{\circ} \mathrm{C}$ while salinity difference is rather significant with middle layer reaching up to 1 ppt difference.

From the sectional distributions of temperature and salinity obtained during March/April (Figures 4 and 5), surface water was dominated by high temperature and low salinity water. The temperature and salinity patterns in section $\mathrm{D}$ (Figures 4(d) and 5(d)) differ from other three sections. In section $\mathrm{D}$, temperature and salinity show inshore to offshore changes. High temperature can be found near coastal area and gradually decrease towards offshore. Meanwhile, low salinity can be found near coastal area and gradually increase towards offshore. Similar to temperature, salinity in section D (Figure 5(d)) also shows inshore to offshore changes where salinity gradually increases towards offshore while other 


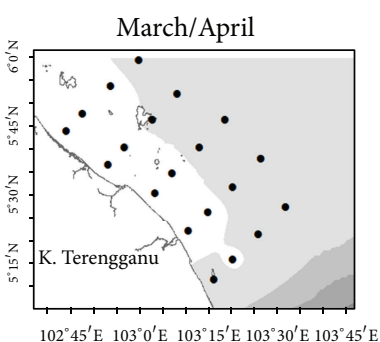

Salinity (ppt)

$\square$ 31.47-31.81 $\square$ 33.19-33.53

$\square 31.82-32.16 \square 33.54-33.87$

$\square$ 32.17-32.50 $\square 33.88-34.21$

$\square$ 32.51-32.84 34.22-34.55

$\square$ 32.85-33.18 $34.56-34.90$

(a)

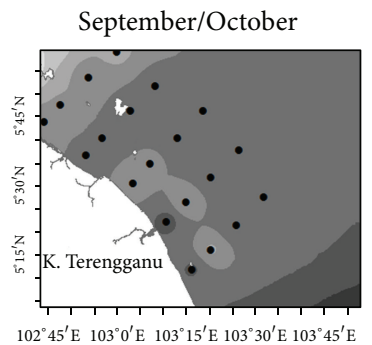

Salinity (ppt)
$\square 31.92-32.08 \square 32.72-32.87$
$\square 32.09-32.24 \square 32.88-33.03$
$\square 32.25-32.40 \square 33.04-33.19$
$\square 32.41-32.55 \square 33.20-33.35$
$\square 32.56-32.71 \square 33.36-33.50$

(e)

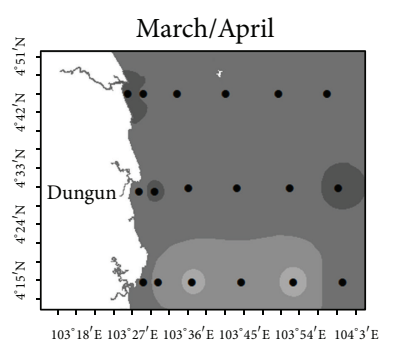

Salinity (ppt)

$\square$ 31.47-31.81 $\square$ 33.19-33.53

$\square$ 31.82-32.16 $\square 33.54-33.87$

$\square$ 32.17-32.50 $\square 33.88-34.21$

$\square$ 32.51-32.84 34.22-34.55

$\square 32.85-33.18 \square 34.56-34.90$

(b)

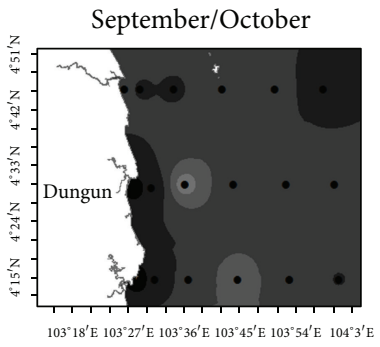

Salinity (ppt)

$\square$ 31.92-32.08 $\square$ 32.72-32.87

$\square$ 32.09-32.24 $\square 32.88-33.03$

$\square 32.25-32.40 \square 33.04-33.19$

$\square$ 32.41-32.55 33.20-33.35

$\square 32.56-32.71 \square 33.36-33.50$

(f)

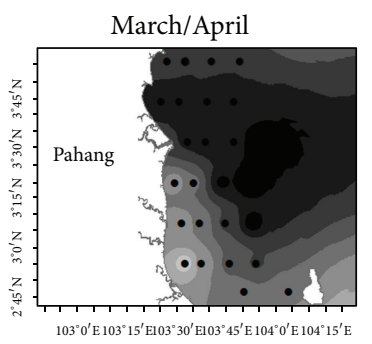

Salinity (ppt)

$\square$ 31.47-31.81 $\square$ 33.19-33.53

$\square$ 31.82-32.16 $\square 33.54-33.87$

$\square$ 32.17-32.50 $\square 33.88-34.21$

$\square$ 32.51-32.84 $\square 34.22-34.55$

$\square$ 32.85-33.18 34.56-34.90

(c)

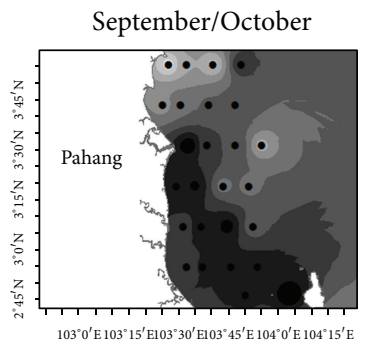

Salinity (ppt)
$\square 31.92-32.08 \square 32.72-32.87$
$\square 32.09-32.24 \square 32.88-33.03$
$\square 32.25-32.40 \square 33.04-33.19$
$\square 32.41-32.55 \square 33.20-33.35$
$\square 32.56-32.71 \square 33.36-33.50$

(g)

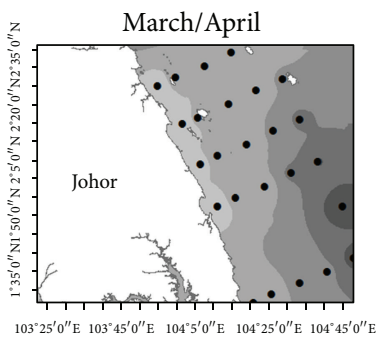

Salinity (ppt)

$\square$ 31.47-31.81 $\square$ 33.19-33.53

$\square 31.82-32.16 \square 33.54-33.87$

$\square 32.17-32.50 \square 33.88-34.21$

$\square$ 32.51-32.84 34.22-34.55

$\square$ 32.85-33.18 $\square$ 34.56-34.90

(d)
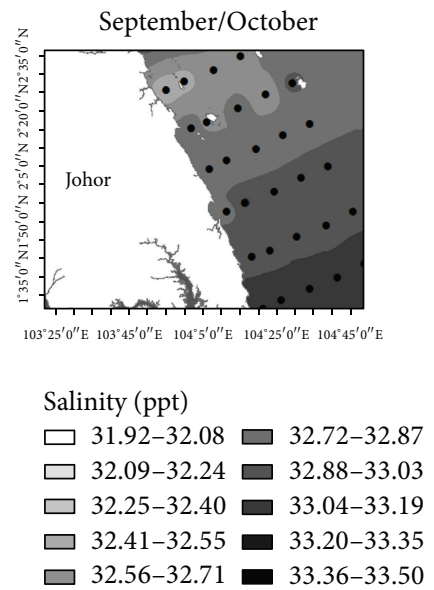

(h)

FIGURE 3: Salinity distribution according to location during March/April and September/October.

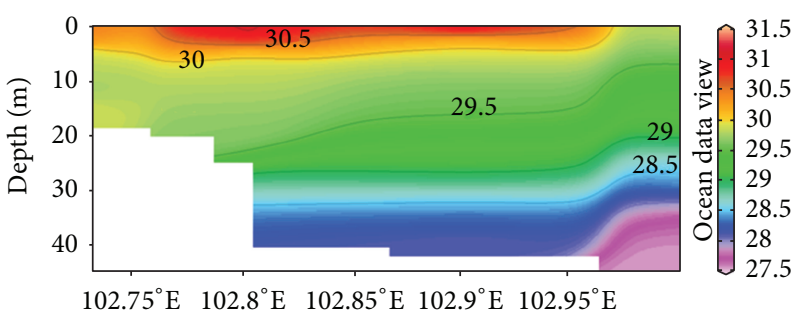

(a)

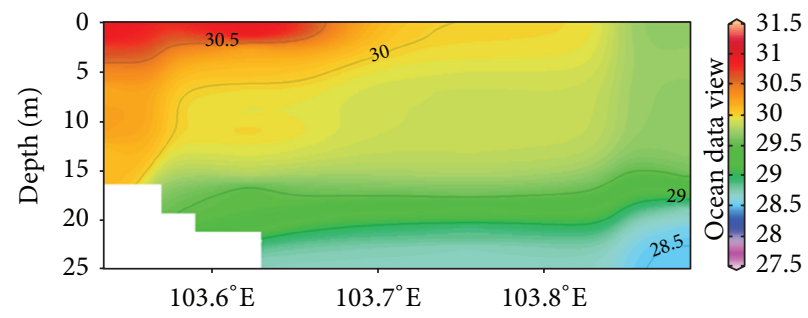

(c)

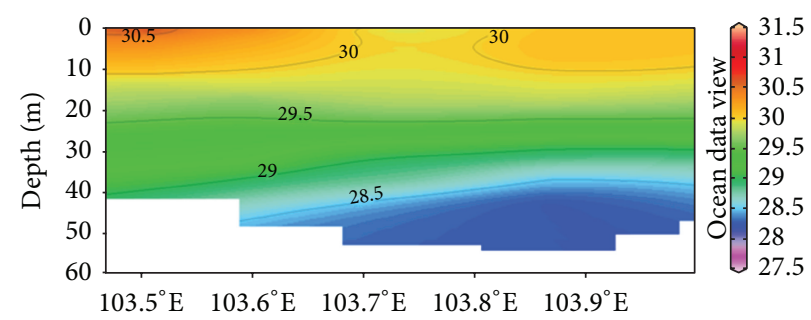

(b)

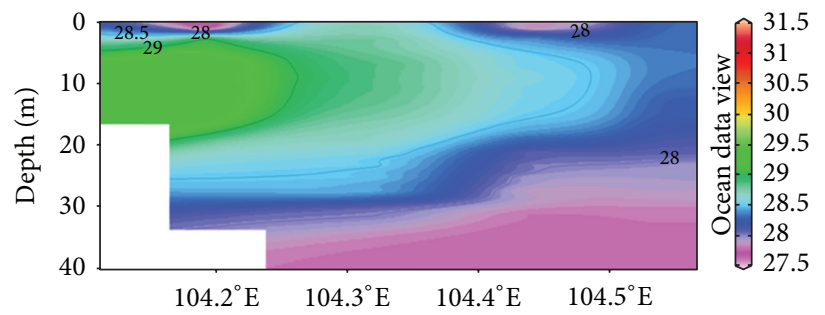

(d)

Figure 4: Vertical distribution of water temperature $\left({ }^{\circ} \mathrm{C}\right)$ at (a) Kuala Terengganu, (b) Dungun, (c) Pahang, and (d) Johor during March-May. 


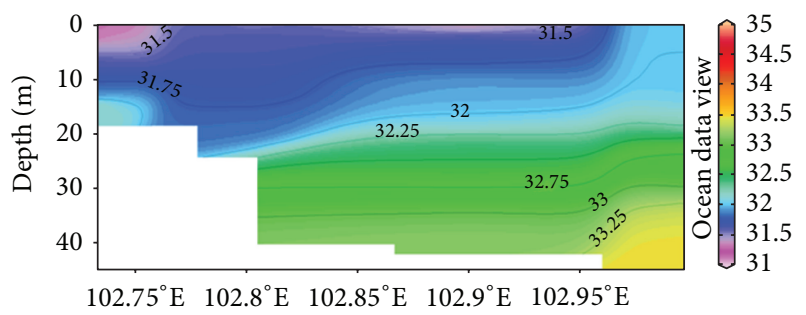

(a)

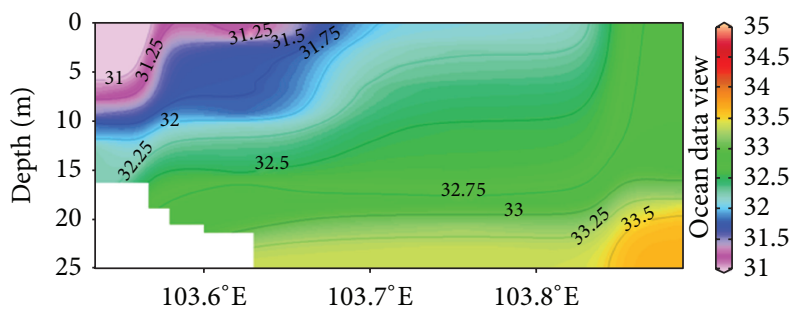

(c)

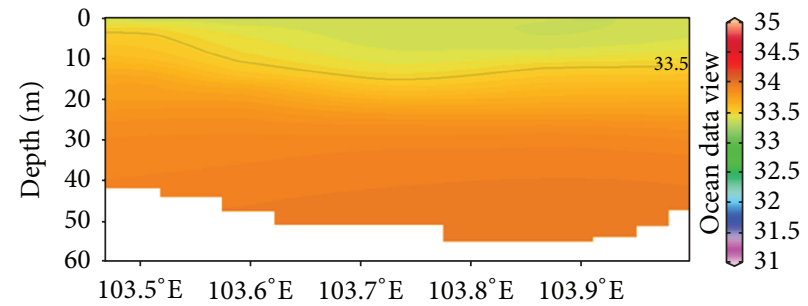

(b)

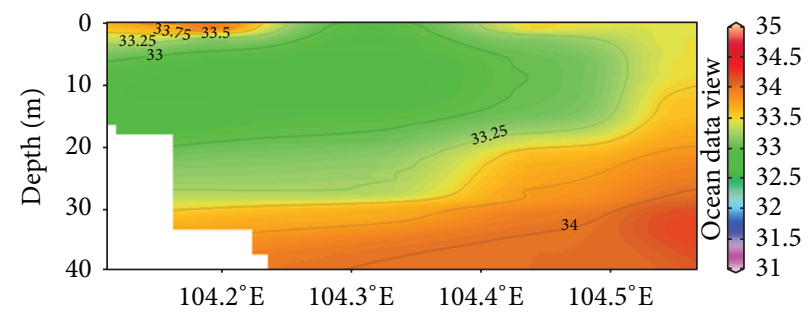

(d)

Figure 5: Vertical distribution of salinity (ppt) at (a) Kuala Terengganu, (b) Dungun, (c) Pahang, and (d) Johor during March-May.

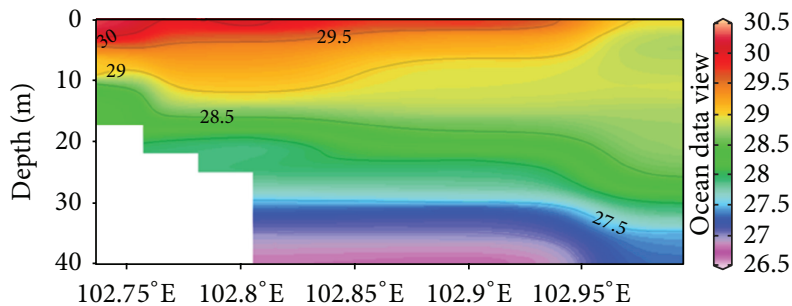

(a)

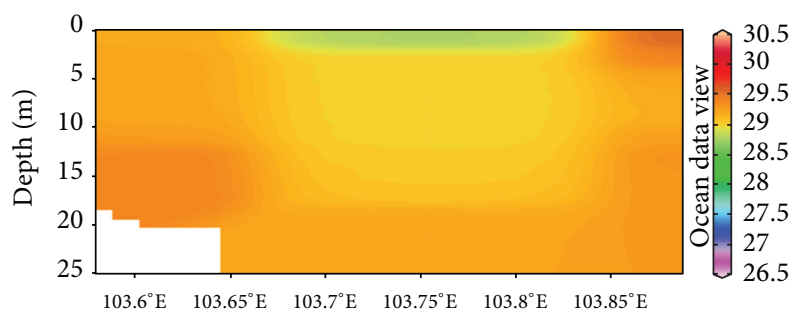

(c)

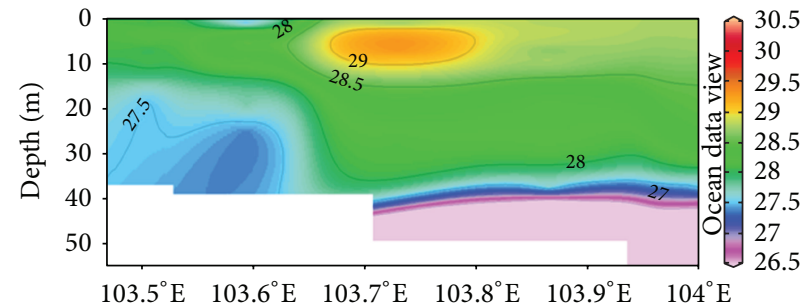

(b)

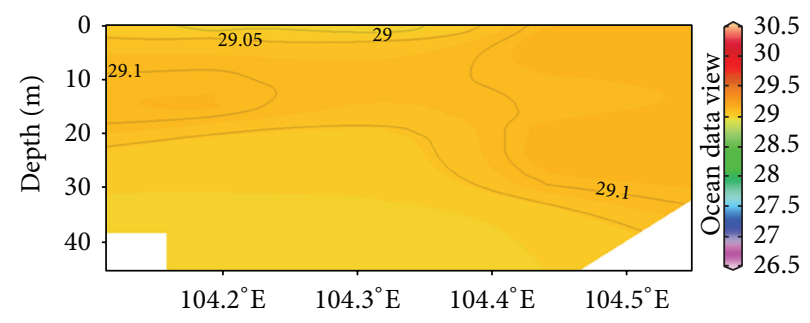

(d)

FIgure 6: Vertical distribution of water temperature $\left({ }^{\circ} \mathrm{C}\right)$ at (a) Kuala Terengganu, (b) Dungun, (c) Pahang, and (d) Johor during SeptemberOctober.

sections shows surface to bottom changes in temperature and salinity. Nevertheless, the overall temperature in section $\mathrm{D}$ is relatively lower to other sections.

In the surface and middle layers during March/April (Figures 4 and 5), the cross-section shows a stratified profile, except for section D. The water column was stratified on surface and middle from both temperature and salinity data. On the other hand, during September/October, most cross-sections are well mixed except for Kuala Terengganu (Figures 6(a) and 7(a)) where stratification is still apparent.
3.2. Current System. During March/April and September/ October, the current circulation of the southern SCS is relatively unknown except for the comprehensive study published by NAGA report [9]. That is the sole study produce based on comprehensive field measurement study. Recently, few attempts were made but based on global ocean model result and numerical modeling analysis $[10,11]$. The data presented from this SCS expedition from 2002 to 2007 can be regarded as one of the most extensive data on current circulation available in the area now. Given the span of years involved in conducting such expedition, the best way to 


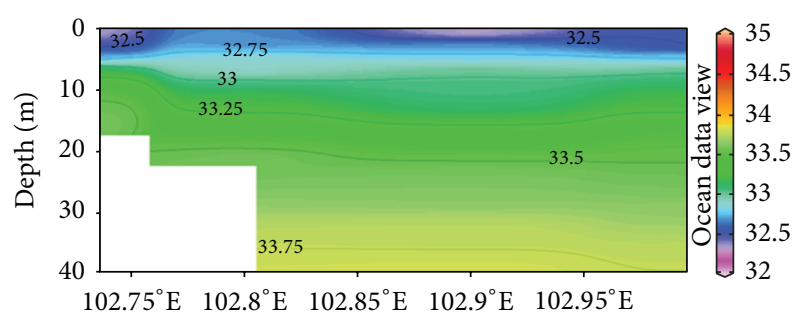

(a)

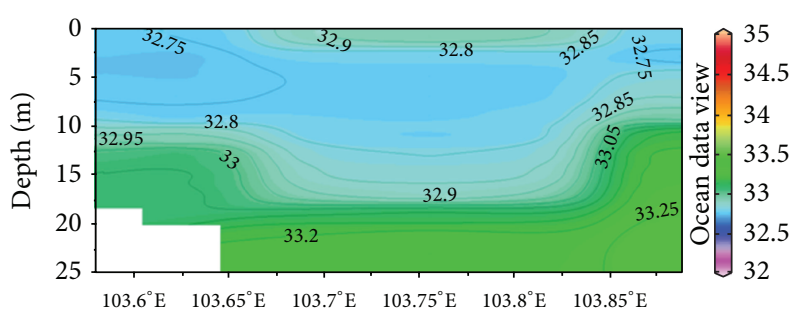

(c)

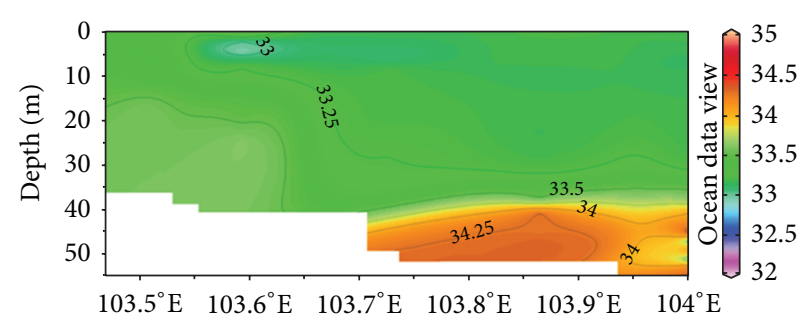

(b)

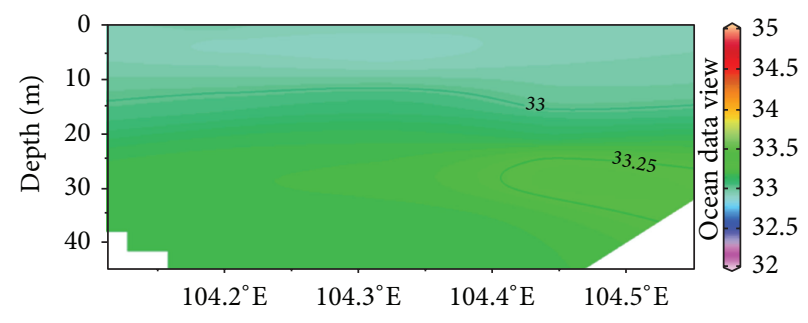

(d)

Figure 7: Vertical distribution salinity (ppt) at (a) Kuala Terengganu, (b) Dungun, (c) Pahang, and (d) Johor during September-October.

present the current data is by conducting composite plot. It is important to note that the current data might have some temporal variations discrepancies in relation to tidal current; nevertheless, the data have shown very good correlation with previous findings [10].

In seasonal reference, March/April and September/October are always being referred to as intermonsoon periods. Nevertheless, from the current direction it can be seen during both periods that the current still possesses the similar direction as northeast monsoon and southwest monsoon accordingly. Previous data $[9,10]$ did show that current during April tends to move southward according to the influence of northeast monsoon circulations, but the intensity is very low to be compared to the circulation during monsoon. Given the fact that the cruise data is a snapshot rather than an average circulation, the influence of coastal region wind variability can be important. Outward flows of current away from the coast are one sign of the local effect which can be seen in Figure 8(a). With seasonal wind being very weak during this period, the influence of local winds can be important. Strong wind towards offshore was recorded along Johor coast during the cruise period (not shown). This has resulted in a very strong current moving towards offshore, which is unlikely to be seen in seasonally average data. This indicates that local wind can be very influential during intermonsoon season when the circulation and wind are weak.

\section{Discussion}

Sea surface temperature and salinity in March/April were higher except in Johor (Figure 2(d)) and lower, respectively, when compared to the values recorded in September/October as shown in Figures 2 and 3. This result is consistent with the results found during the SEAFDEC hydrographic expedition during 1995-96. Yanagi et al. [7] published a significant input of southern SCS water characteristics analysis from the cruise which shares the same sampling month as to this study. The seasonal variations of vertical profile from temperature and salinity value found from SEAFDEC cruise are also similar to what are found during this SCS expedition. This similarity is also found during the historical cruise during the 1960s known as NAGA cruise [9]. In general, the data of water characteristics from 3 different cruises of different years suggest that the seasonal variations of water temperature and salinity from this SCS expedition that are presented in this study are not unique phenomena during the particular year of sampling but typical to the general characteristics of the area. Nevertheless, given the amount of stations and coverage of the datasets, certain details which are not presented previously can be seen from the results.

Based on Figures 2 and 3, temperature and salinity pattern change mostly in meridional direction. However, in Johor coast, during March/April they change from inshore to offshore. This particular difference correlates well with current and wind data where, during a particular period, current moves offshore with relatively strong magnitude (Figure 8(a)).

Water temperature during April is believed to be higher because of large sea surface heating and weak sea surface wind [7]. A recent study also found that wind pattern is much weaker during months of April and May [3]. Large sea surface heating and weak sea surface wind will also result in the development of stratifications. Stratification profile at cross-sections during March/April data as presented in Figure 4 is coherent with these reasons. Quantitatively, surface temperature relies not only on the surface heat flux and wind stress but also on horizontal heat transport. Overall current during the intermonsoon period is relatively low. This slow current movement to induce mixing is one of the reasons why stratification is present during this period. Data from Johor coast during March/April is unique compared to 


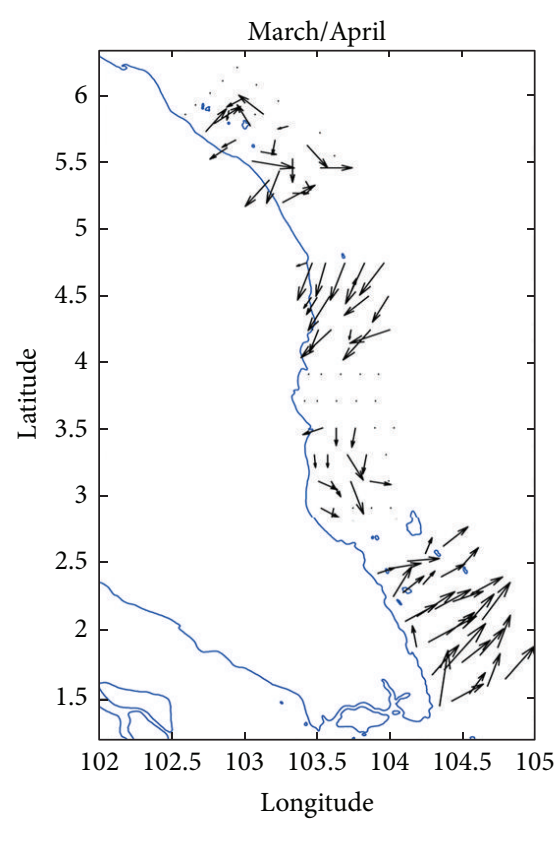

$\longrightarrow 0.5 \mathrm{~m} / \mathrm{s}$

(a)

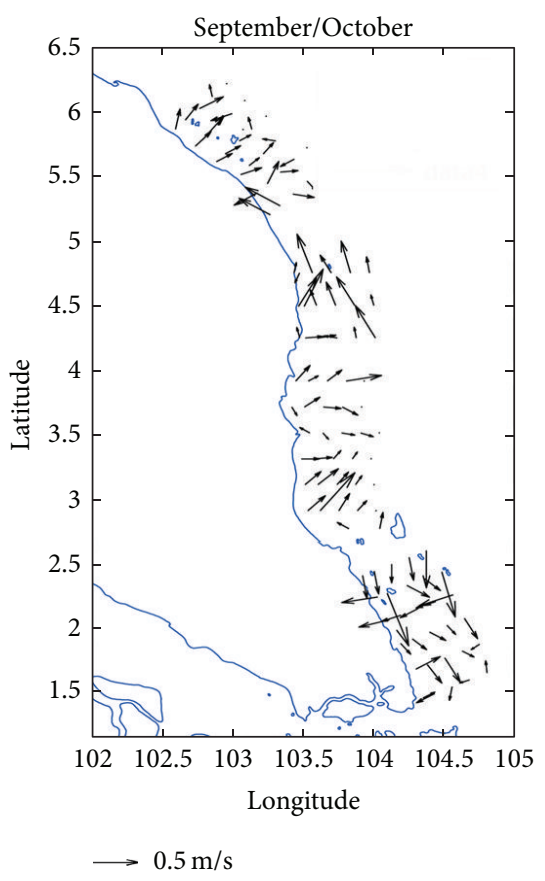

(b)

FIGURE 8: Composite plot for surface current during March-April and September-October.

other places. From the cross-section, well-mixed layer can be observed as a result of strong wind and current, which enhance mixing in the area.

During September/October, temperature is lower and salinity is higher. Heavy rainfall and lower solar radiation due to overcast skies is one of the factors [6]. The sea surface heating weakened as the season approached September/October and stratification starts to vanish. This process will continue with cooling of surface temperature and increase in wind stress until it reaches northeast monsoon season (December/January). Although there is no study of rainfall volume or river discharge in this study, overview data from the Meteorological Office (not presented) does show increase of rainfall during September/October. The effect of higher river discharge is one of the main factors causing stratification to weakened especially near the coastal area. Nevertheless, the effect of river discharge might only give little effect to the water profile because the previous study on the area of southern SCS did suggest that the main driver of seasonal characteristics of the sea water is mainly controlled by sea surface heat flux and sea surface wind [7].

Interestingly, although both March/April and September/October sit in the intermonsoon season, the behavior of the current circulation shows characteristics of both northeast and southwest monsoon season accordingly. This is believed to be a continuation of the monsoon driven current. However, the previous study found that, during this particular period, current is slower and produces very limited mixing [10]. Because of this low current circulation in the East Coast, Peninsular Malaysia encounters low rainfall and clear

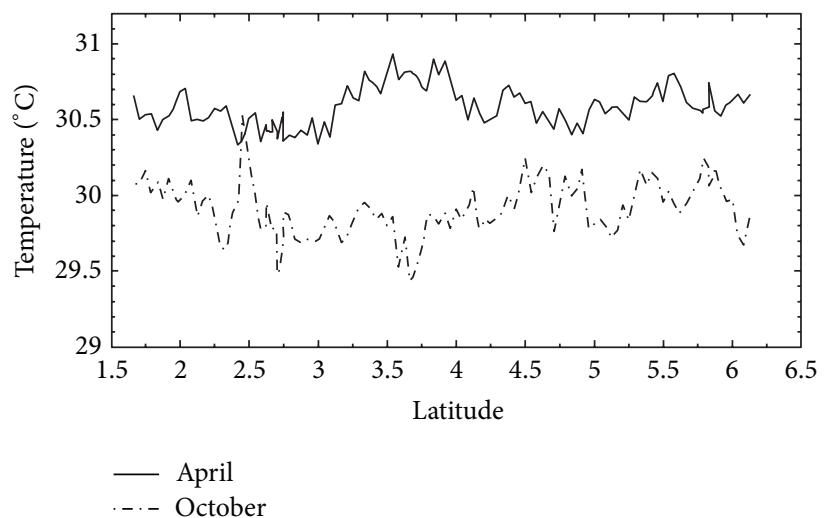

Figure 9: Average sea surface temperature from Aqua MODIS data of $4 \mathrm{~km}$ resolution.

skies. High temperature in most location due to large surface heating and weak sea surface wind enhances the development of stratification [7].

Additional studies were conducted by using Aqua MODIS data to get comprehensive data coverage along the study area to better visualize the difference properties between months of April and October. In this study, SST data from 2003 to 2007 were used for further analysis. Figure 9 shows average of five-year Aqua MODIS sea surface temperature (SST) along east coast of Peninsular Malaysia. Data of five years average were presented to demonstrate the overview of sea surface temperature difference between April and October. From the graph (Figure 9), the difference 

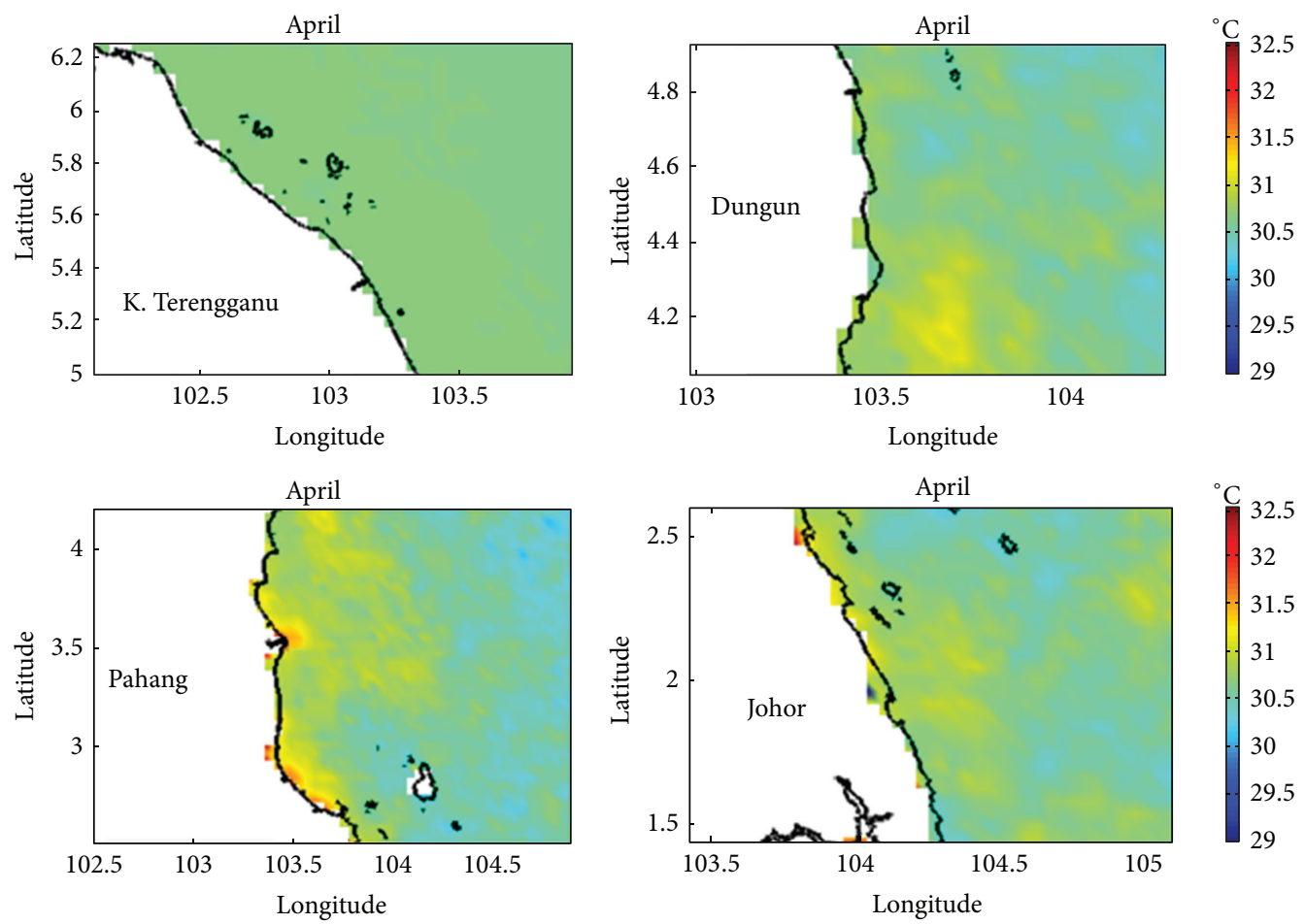

(a)
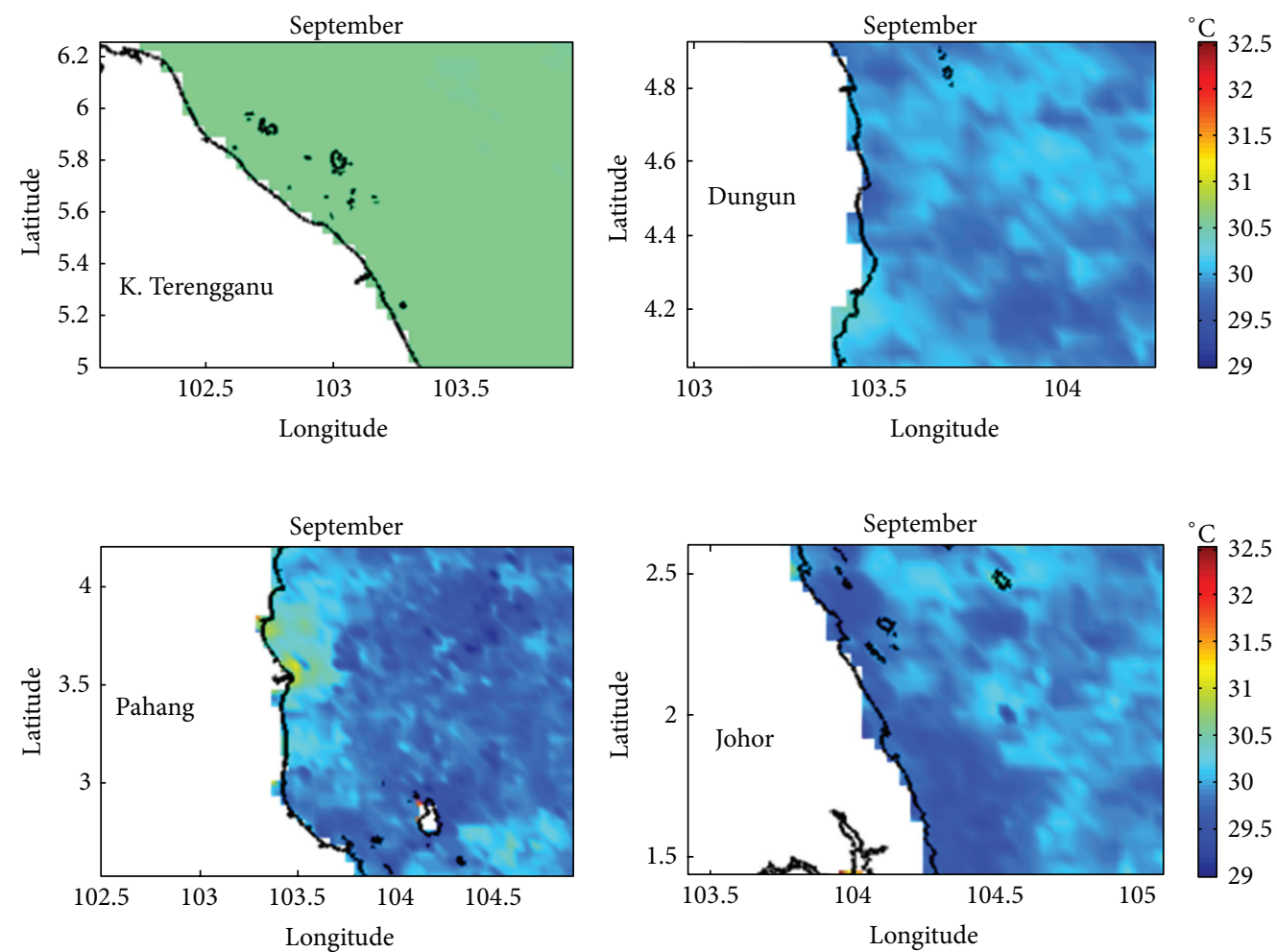

(b)

FIGURE 10: Map of average 10-year Aqua MODIS sea surface temperature. 
during the two months can be clearly seen. During April, sea surface temperature is higher compared to the sea surface temperature during October.

The Map of five-year monthly average Aqua MODIS SST in April and October is shown in Figure 10. As discussed earlier, during March/April the water is usually less saline and higher in temperature. In general, SCS exhibits strong seasonal variability in its fronts which are monsoon related [12]. The patterns of the seasonal variability can be clearly seen in Figure 10. During April, the coastal water surface temperature is high. The high temperature sea surface distribution covers almost the entire Peninsular Malaysia with some particular areas near Terengganu and Pahang recorded as having very high temperature. The opposite was observed in October data. MODIS data show lower temperature covering the coastal area especially near the southern part. As we move further north temperature increases slightly. During both periods, area near the Pahang River $\left(3.5^{\circ} \mathrm{N}\right)$ outflow shows higher temperature water. The same was observed near Terengganu River $\left(5.5^{\circ} \mathrm{N}\right)$, but the size is smaller. The result is consistent with Yanagi et al. [7] that river discharge in some extent influences the stratification of the surrounding waters. From the MODIS data, surface temperature provides some insight into how river discharge influence area only close to the coast and has very little impact on the offshore area.

\section{Conclusion}

Intermonsoon water characteristics between the two periods of sampling, March/April and September/October show some seasonal variations. Temperature during September/October, is lower and salinity is higher to be compared to the data during April/March. Supporting data from MODIS show that seasonal change is believed to be caused by sea surface heat flux and sea surface wind. Higher sea surface heat flux during March/April caused the surface water temperature to increase, and at the same time stratification was present because of low mixing as a result of a low wind stress during that period. On the other hand, water is mostly well mixed during September/October. High overcast skies and higher precipitation reduce surface temperature, while high river influx resulting from precipitation weakens the stratification.

Current circulation is believed to have some effect on the distribution of water characteristics, especially in allowing for stratification or inducing mixing. Johor coast is one of the examples of how local wind variability can induce strong impact on current movement and mixing which subsequently overcome stratification. It is also quite clear that intermonsoon season still maintains characteristics of the prior monsoon seasons but relatively weaker. This study provides an important overview of the current circulation and its influence towards physical parameters. Although it is far from complete, the information provided from this field data is vital for the area where very limited amount of field data is available.

\section{Conflict of Interests}

The authors declare that there is no conflict of interests regarding the publication of this paper.

\section{Acknowledgments}

This study was jointly supported by the Higher Institution Centre of Excellence (HICoE) Research Grant, under the Institute of Oceanography and Environment (INOS), and the National University of Malaysia Long-Term Research Grant: LRGS/TD/2011/UKM/PG/01. The authors would like to acknowledge the Institute of Oceanography (INOS), UMT, and all scientists and crew members involved in the South China Sea Expedition spanning from 2002 to 2007.

\section{References}

[1] W. Fang, Z. Guo, and Y. Huang, "Observational study of the circulation in the southern South China sea," Chinese Science Bulletin, vol. 43, no. 11, pp. 898-905, 1998.

[2] P. C. Chu, N. L. Edmons, and C. Fan, "Dynamical mechanisms for the South China sea seasonal circulation and thermohaline variabilities," Journal of Physical Oceanography, vol. 29, no. 11, pp. 2971-2989, 1999.

[3] M. F. Akhir and Y. J. Chuen, "Seasonal variation of water characteristics during inter-monsoon along the East Coast of Johor," Journal of Sustainability Science and Management, vol. 6, no. 2, pp. 206-214, 2011.

[4] N. Hendiarti, C. G. F. Marina, and S. Albertus, "Satellite view of Southern South sea: natuna islans and its surrounding water," in Satellite Remote Sensing of South China Sea, chapter 14, pp. 211-228, Tingmao, Taiwan, 2008.

[5] K. Taira, M. N. B. Saadon, S. Kitagawa, and T. Yanagi, "Observation of temperature and velocity in the coastal water off Kuala Terengganu, Malaysia," Journal of Oceanography, vol. 52, no. 2, pp. 251-257, 1996.

[6] M. N. Saadon and A. Camerlengo, "Interannual and seasonal variability of the mixed layer depth of the South China sea," in Proceedings of the National Conference on Climate Change, Universiti Putra, Malaysia, 1994.

[7] T. Yanagi, S. I. Sachoemar, T. Takao, and S. Fujiwara, "Seasonal variation of stratification in the gulf of Thailand," Journal of Oceanography, vol. 57, no. 4, pp. 461-470, 2001.

[8] W. Fang, G. Fang, P. Shi, Q. Huang, and Q. Xie, "Seasonal structures of upper layer circulation in the southern South China sea from in situ observations," Journal of Geophysical Research C, vol. 107, no. 11, pp. 1-12, 2002.

[9] K. Wyrtki, "Physical oceanography of the Southeast Asian waters," Naga Report, Scripps Institution of Oceanography, San Diego, Calif, USA, 1961.

[10] M. F. Akhir, "Surface circulation and temperature distribution of Southern South China sea from global ocean model (OCCAM)," Sains Malaysiana, vol. 41, no. 6, pp. 701-714, 2012.

[11] F. T. Tangang, C. Xia, F. Qiao, L. Juneng, and F. Shan, "Seasonal circulations in the Malay Peninsula Eastern continental shelf from a wave-tide-circulation coupled model," Ocean Dynamics, vol. 61, no. 9, pp. 1317-1328, 2011.

[12] M. Lee and Y. Chang, "SST fronts in the South sea," in Satellite Remote Sensing of South China Sea, chapter 12, pp. 187-198, Tingmao, Taiwan, 2008. 

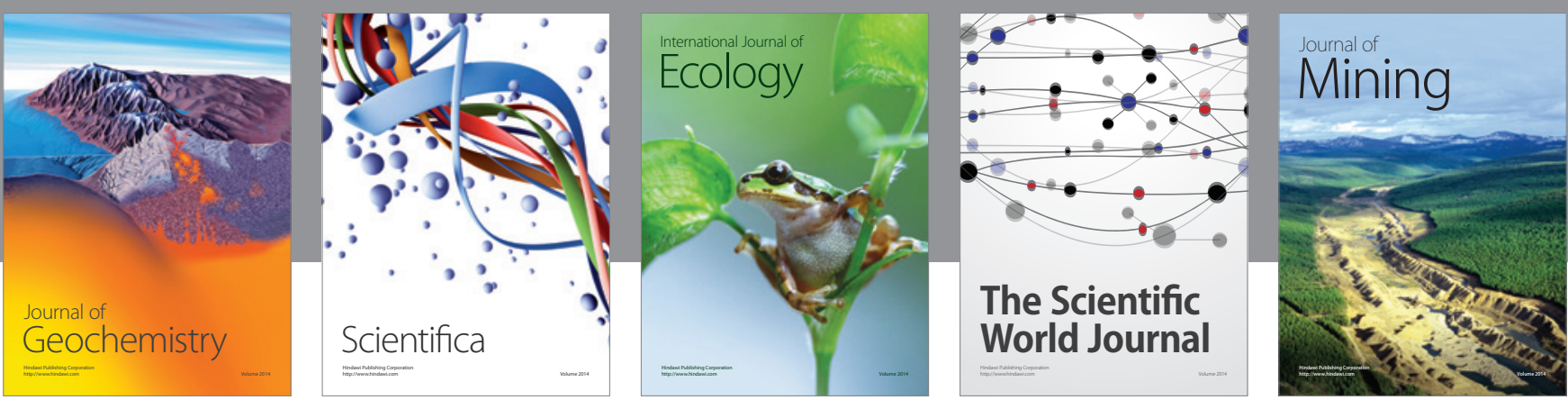

The Scientific World Journal
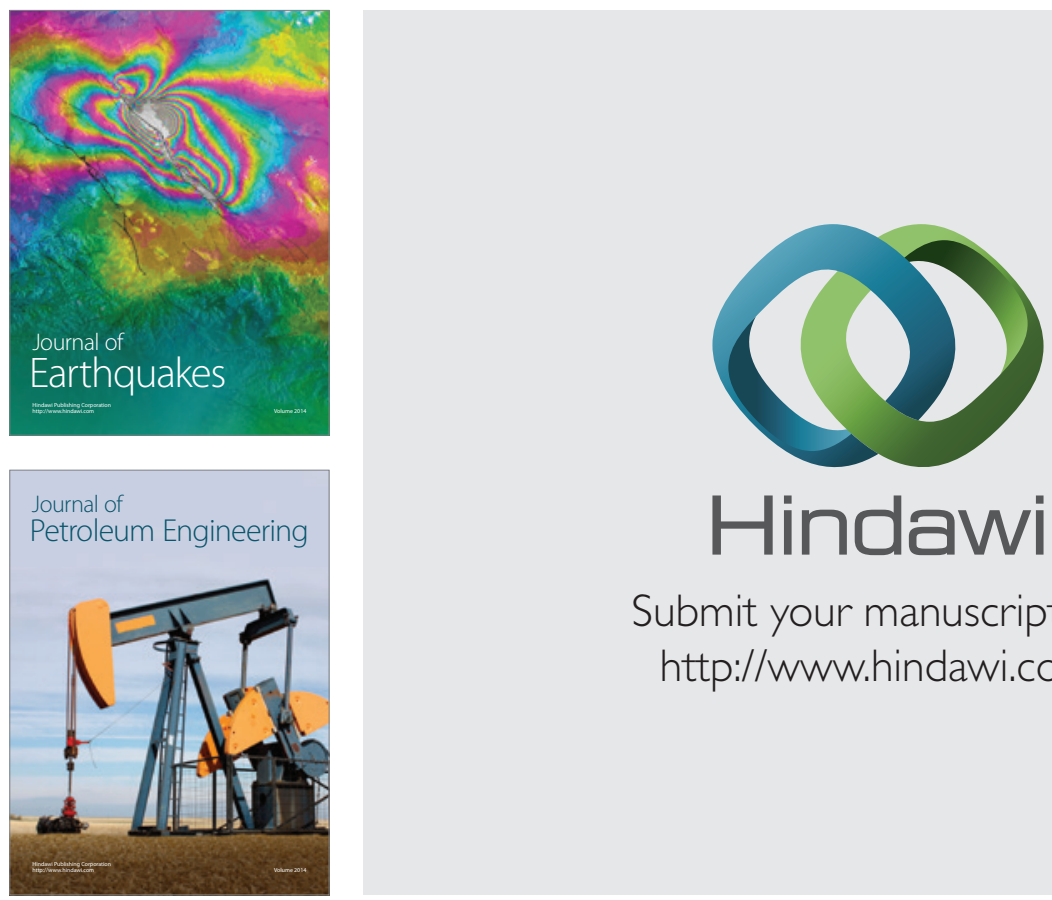

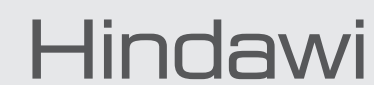

Submit your manuscripts at

http://www.hindawi.com
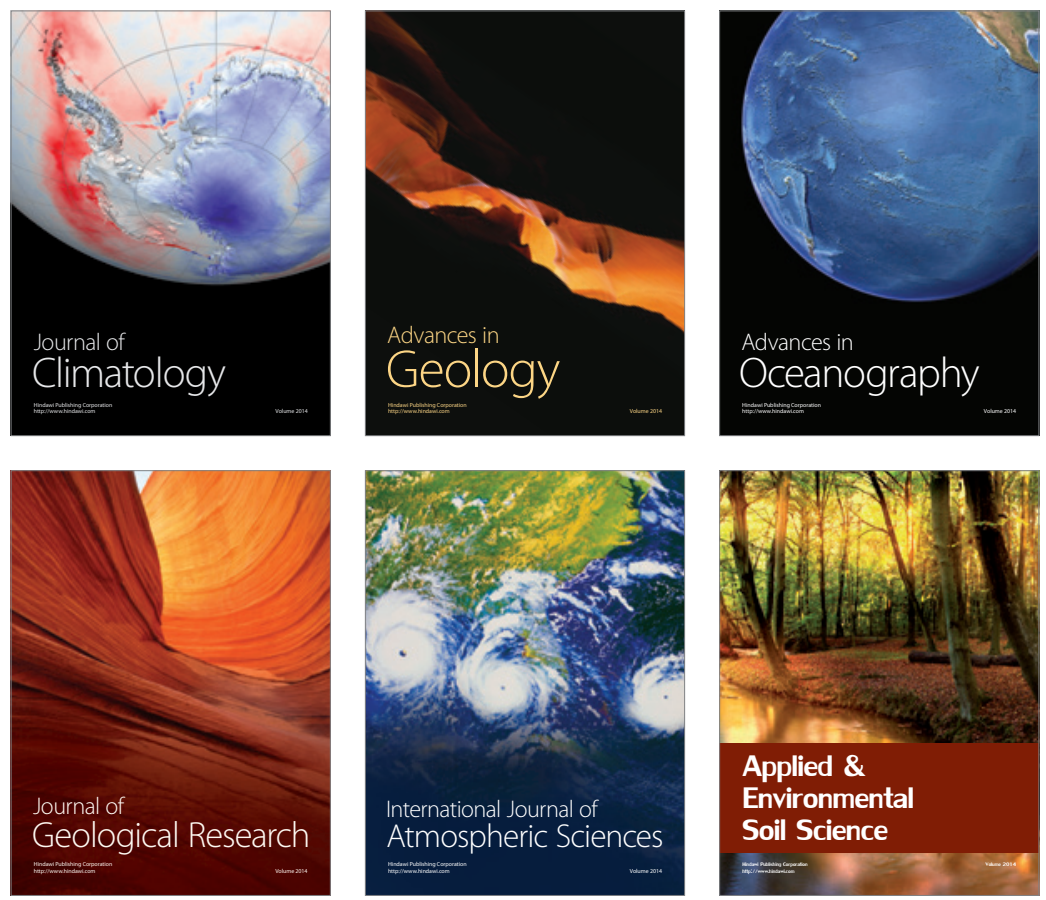
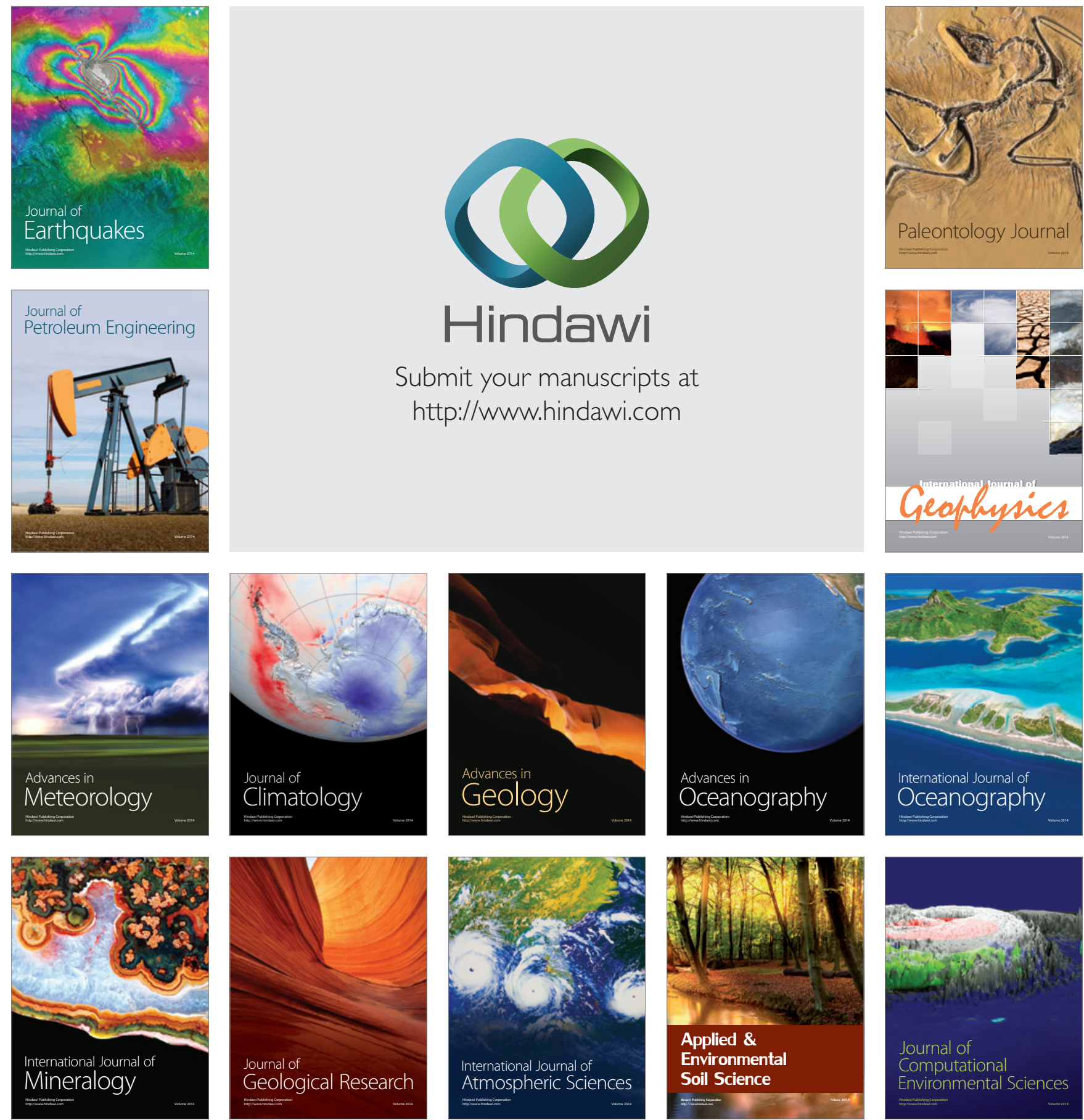